\title{
Comparing Behavioral Theories to Predict Consumer Interest to Participate in Energy Sharing
}

\author{
Julia Morgan (D) and Casey Canfield *(D) \\ Department of Engineering Management \& Systems Engineering, Missouri University of Science \& Technology, \\ Rolla, MO 65409, USA; jmw8q@mst.edu \\ * Correspondence: canfieldci@mst.edu
}

Citation: Morgan, J.; Canfield, C. Comparing Behavioral Theories to Predict Consumer Interest to Participate in Energy Sharing. Sustainability 2021, 13, 7693. https://doi.org/10.3390/su13147693

Academic Editors: Francesca Grippa, Monica Baraldi Borgida,

Youngbok Ryu and Richard Swanson

Received: 7 May 2021

Accepted: 6 July 2021

Published: 9 July 2021

Publisher's Note: MDPI stays neutral with regard to jurisdictional claims in published maps and institutional affiliations.

\begin{abstract}
Consumer investment in distributed energy resources (DERs) is increasing the penetration of renewable energy in the grid. In some cases, DERs produce more electricity than needed by the owner and this excess electricity is sold to the utility (e.g., net metering). In contrast, energy sharing allows a facilitator, which may or may not be the utility, to redistribute excess renewable electricity to fellow community members directly. However, little is known about consumer interest in participating in this type of arrangement. This preregistered study uses structural equation modeling to compare two behavioral theories, Value-Belief-Norm and Diffusion of Innovation, to predict consumer interest in participating in energy sharing. Participants answered questions about energy sharing in the context of an energy-sharing community facilitated by the fictional company, E-topia. Survey data from 195 online participants suggest that Value-Belief-Norm is a better, although not quite acceptable, fit. This suggests that early adoption of energy sharing may be driven by appealing to core values rather than novelty-seeking. This study implies that individuals are more likely to participate in a new technology system such as energy sharing when the effects of participation align with individuals' values.
\end{abstract}

Keywords: energy sharing; value-belief-norm; diffusion of innovation; renewable energy; renewable energy community; sharing economy; sustainable change

\section{Introduction}

As prices have decreased, interest in renewable energy has increased [1]. However, many consumers still face barriers to renewable procurement. One emerging strategy is energy sharing. Energy sharing provides a platform for electricity exchange between gridconnected participants in a specific region, such as a neighborhood [2]. However, energy sharing is limited to the community participants that subscribe to the service. Energy sharing, sometimes referred to as "energy communities", has been demonstrated in the United States [3], but there is higher interest and scholarship in Europe (e.g., Austria [4], Poland [5], and Portugal [2]). To date, little is known about what factors influence interest in participating in energy sharing, particularly in the U.S. market.

Energy-sharing management systems facilitate interactions between energy-sharing participants to maintain grid stability. Energy-sharing management systems can be incorporated into energy distribution systems as a way to decentralize the traditional hierarchical system [6]. Energy-sharing participants rely on the energy-sharing management system to coordinate transactions between participants while maintaining system balance [7]. End-users that invest in distributed energy resources (DERs), such as solar, are prosumers because they have the ability to both consume and produce electricity [8]. In contrast, consumers can only consume electricity. Consumers are encouraged to participate in energy-sharing communities because prosumers set their own, typically lower than retail, price to sell excess electricity. This allows consumers to purchase electricity at a reduced cost [9]. By redistributing excess prosumer electricity, prosumers are optimizing their investment by minimizing curtailment while also improving utility resource allocation $[10,11]$. 
Curtailment occurs when there is more generation (or supply) than demand for electricity, particularly when renewable generation is limited due to concerns about grid stability [12], leading to inefficiencies [13]. This is in contrast to the behavioral definition of curtailment in the context of energy conservation [14].

In this study, consumer interest in participating in energy sharing is predicted using two behavioral theories, (1) value-belief-norm (VBN) and (2) diffusion of innovation (DOI), which are particularly relevant for new and emerging technologies. We use structural equation modeling, a statistical technique to measure relationships between observed and latent variables, to determine which behavioral theory has the better fit with the data [15].

\section{Predicting Energy Sharing Participation}

Energy-sharing facilitators are interested in predicting end-user interest to participate in energy-sharing communities. The energy-sharing facilitator may be the utility, a thirdparty for-profit, or a third-party non-profit organization. Predictions provide the facilitator with information to maximize energy-sharing system connectivity while minimizing loss and solar curtailment [16]. Participation and community engagement have been examined for business models [4,17], optimization [18,19], and demand side experience [20]. However, each of these approaches emphasizes the characteristics of the service provided to the end-user without consideration of end-user decision-making strategies, which may not be purely rational processes. To date, little research has investigated the correlations between consumer attitudes, values, and perceptions with interest in participating in an energy-sharing service. Conradie et al. (2021) found that attitudes toward renewable energy are a significant factor when determining consumer intent to participate in a renewable energy community [21]. This is consistent with Wolske et al.'s (2017) findings that favorable attitudes about the technology provide a good representation of interest, because attitude takes into consideration both intrinsic and extrinsic motivations [22]. Better understanding consumer preferences can benefit a potential energy-sharing facilitator by opening up opportunities to customize the service to best suit a community's needs.

To date, most research on energy sharing has focused on technology development. A few studies have used optimization as an approach for predicting interactions between communities. Liu \& Guo (2017) predict interactions of integrated direct current-linked microgrids [23]. Using smart systems in the Internet of Things (IoT), an optimization model developed for an energy management system is used to increase the usage of renewable energy [24]. In order to encourage autonomous activity, Islam et al. (2020) developed an optimization-based algorithm to improve grid resilience [18]. However, these studies fail to accurately represent the dynamics of consumer adoption and potential implications for the energy-sharing system.

Behavioral theories have been applied to sharing economy topics, such as acceptance of electric vehicle sharing [25] and energy conservation behavior [26,27]. In a comprehensive examination of potentially relevant theories, Wolske et al. (2017) predict solar adoption using structural equation modeling leveraging aspects from VBN, DOI, and the Theory of Planned Behavior (TPB) [22]. Due to the novelty of the technology and business model, little work has focused on energy sharing directly.

\section{Behavioral Theories}

\subsection{Value-Belief-Norm}

VBN uses three factors-values, beliefs, and norms-to explain consumer behavior [28]. VBN combines value theory, which identifies the importance of attributes, with the norm-activation model, which explains altruistic and environmentally friendly behavior $[29,30]$. VBN was initially created to explain peoples' actions based on personal obligation and self-expectations [31].

In previous studies, VBN was useful for predicting pro-environmental behavior [32], willingness to pay for the reduction of noise pollution [33], and environmental activism [34]. Stern et al. (1999) used VBN to explain support for social movements and they found 
that an individual will support a movement when their values are threatened, and the individual believes their actions can assist in the restoration of threatened values [31]. Andersson et al. (2013) used VBN to investigate students' attitudes toward sustainable development through Education for Sustainable Development (ESD) and they found that almost all attitudes and perceptions of sustainable development are positively impacted by ESD because it aligned with student values [35]. VBN is often criticized for not predicting actual behavior (i.e., attitude-behavior gap) and not adequately addressing non-moral motivations [36]. As a result, it is often combined with other theories [37].

In the context of energy sharing, VBN can be used to predict consumer interest in participating in sustainable systems. VBN uses environmental values, in conjunction with awareness of consequences, to explain the outcome of interest. Environmental values are addressed by providing access to additional renewable electricity. Consumers may have internal obligation, or feelings of obligation to act in a way consistent to their morals and values. If VBN is the best fitting theory, this suggests that values are critical for predicting interest in energy sharing.

\subsection{Diffusion of Innovation}

DOI uses the dissemination of new technologies or ideas to explain consumer perceptions and interest [38]. DOI acknowledges the characteristics of innovation and communication channels associated with the diffusion process [39]. These features allow for successful diffusion of designs and inventions. Both perceived innovativeness and the effectiveness of communication channels predict interest in the innovation [40].

Previous research used DOI to predict acceptance of new technologies related to the education system [41], health care innovation [42], and sustainable systems [43]. Al Othman \& Sohaib (2016) used DOI to enhance innovation and sustainability of Saudi firms [44]. Participation in local business models like energy sharing is emphasized by DOI because of the increase of efficiency and representation of participants [45]. DOI is often criticized for being limited to specific technological and social conditions [46]. Similar to VBN, it is often used as a building block for more complex integrated models. No studies used DOI to predict consumer participation in energy-sharing communities.

In the context of energy sharing, DOI can explain consumer interest in participating in a novel approach to energy distribution. Though decentralized systems are a wellknown approach, like blockchain or restaurant chains, energy sharing has yet to become highly commercialized. If DOI is the best-fitting theory, this suggests that organizations should target technologically savvy areas full of early adopters of new innovations for energy-sharing communities.

VBN and DOI focus on different aspects of the decision-making process (see Table 1). Attitude refers to consumer emotions, beliefs, and behaviors that will influence decision making. External influences include communication channel factors while internal influences are factors related to culture and values. Moral considerations refer to the sense of obligation to benefit others because one has already received a benefit [22]. Change over time refers to the adoption rate of a product or service over a certain period of time [47]. As shown in Table 1, VBN takes into consideration attitude, external influences, internal influences, and moral considerations when explaining consumer actions. By using VBN to explain consumer intention to participate in energy sharing, consumers are expected to make decisions in accordance with individual values and beliefs. This is appropriate for energy sharing because participation in an energy-sharing community is reliant on consumer environmental values. DOI takes into consideration external influences, internal influences and change over time. As technology improves and prices decrease, the incorporation of energy sharing technologies (e.g., solar panels, smart meters) will increase. This diffusion of technology happens over a certain period of time, which justifies the use of DOI in this study. 
Table 1. Comparison of key factors included in Value-Belief-Norm (VBN) and Diffusion of Innovation (DOI).

\begin{tabular}{cccccc}
\hline Attitude & $\begin{array}{c}\text { External } \\
\text { Influences }\end{array}$ & $\begin{array}{c}\text { Internal } \\
\text { Influences }\end{array}$ & $\begin{array}{c}\text { Moral } \\
\text { Considerations }\end{array}$ & $\begin{array}{c}\text { Change over } \\
\text { Time }\end{array}$ \\
\hline VBN & $\mathrm{X}$ & $\mathrm{X}$ & $\mathrm{X}$ & $\mathrm{X}$ & \\
\hline DOI & & $\mathrm{X}$ & $\mathrm{X}$ & & $\mathrm{X}$ \\
\hline
\end{tabular}

\section{Materials and Methods}

\subsection{Recruitment}

We recruited 200 participants on Prolific for a study on "energy sharing technology" in February 2021. Prolific is an online platform used to recruit participants for scientific studies, similar to Amazon Mechanical Turk (MTurk) [48]. However, Prolific provides more diverse participants [49] that better represent the demographics of national samples [50]. This sample size is consistent with the recommended minimum sample size to ensure adequate power [51,52]. Eligible participants were current residents of the United States and at least 18 years old. All participants were paid $\$ 3$ for a 15-20 min survey. Participants provided informed consent before they participated in the study. At the end of the survey, participants were given the opportunity to state whether we should use their data. Participants may choose not to recommend use of their data for a variety of reasons including being busy or distracted during the survey.

\subsection{Measures}

The survey measured variables related to VBN and DOI consistent with other researchers [17]. In general, most scales were measured on a 5-point Likert scale [31], where $1=$ strongly disagree and 5 = strongly agree. We also included an "I don't know" option to avoid over-estimation at the neutral point of the scale [53]. This was particularly important, given that energy sharing is a new technology that participants might be unfamiliar with Responses of "I don't know" were treated as missing values. The scales are described in the text and the confirmatory factor analysis is summarized in Tables A1-A3.

Ultimately, the outcome variable is interest in energy sharing. This is estimated by the factor loadings of four questions that measure interest, "I would be happy to participate in energy sharing even if I have to pay for the total cost", "I would switch to energy sharing if I was considering changing my electricity supplier", "I would support having energy sharing in my area", and "I have a positive overall evaluation of energy sharing" (Cronbach's $\alpha=0.81$ ). Since participants would have few opportunities to participate in energy sharing in the real world, we did not include a measure of behavior due to concerns about validity.

As a precursor to interest in energy sharing, we measured social curiosity. This is measured by three items to estimate interest in learning about costs and benefits if a friend, family member, or neighbor participated in energy sharing "I would be interested in learning about the cost and benefits of energy sharing if a [friend/family member/neighbor] participated in energy sharing" (Cronbach's $\alpha=0.87$ ). Social curiosity is a weaker version of interest that relies on perceptions of the social environment [54].

\subsubsection{Value-Belief-Norm}

VBN includes estimates of values, which predict beliefs, which predict norms, which predict social curiosity and interest. Values include altruism, self-interest, traditional values, and openness to change. All measures were consistent with the standard items from the literature [55]. Biospheric and social altruism is measured by four items evaluated on a 5point Likert scale where $1=$ not important and $5=$ extremely important with an additional "opposed to my values" option (coded as -1). Participants report how closely each statement resembles guiding principles in their life. The statements include "Respecting the Earth, harmony with other species", "Protecting the environment, preserving nature", 
"A world at peace, free of war and conflict", and "Unity with nature, fitting into nature" (Cronbach's $\alpha=0.90$ ). Similarly, self-interest is measured by three statements including "Wealth, material possessions, money", "Authority, the right to lead or command", and "Influential, having an impact on people and events" (Cronbach's $\alpha=0.73)$. Traditional values include three statements, "Honoring parents and elders, showing respect", "Family security, safety for loved ones", and "Self-discipline, self-restraint, resistance to temptation" (Cronbach's $\alpha=0.74)$. Openness to change is measured by three statements including "Curious, interested in everything, exploring", "A varied life, filled with challenge, novelty, and change", and "An exciting life, stimulating experiences" (Cronbach's $\alpha=0.85$ ).

To measure beliefs, awareness of consequences is estimated by a single item, "Climate change is a serious problem for society." Wolske et al. (2017) found that a single-item was sufficient due to the existence of strong, polarized views on climate change [22]. Their analysis suggests that using a single item here does not affect the estimation of relationships between other variables. To measure norms, personal norm is estimated by 3 items, "I feel a personal obligation to do my part to move the country to a renewable energy future", "I feel a personal obligation to do my part to prevent climate change", and "I feel guilty when I waste energy" (Cronbach's $\alpha=0.90$ ).

\subsubsection{Diffusion of Innovation}

DOI presumes that consumer innovativeness and communication channels influence the perceived characteristics of the innovation, which predict social curiosity and interest. Consumer innovativeness is comprised of consumer novelty seeking [56] and consumer independent judgement making [57]. Consumer novelty seeking is measured by three items that include "I continuously look for new experiences from new products", "I continuously look for new products and brands", and "I like to visit places where I'm exposed to information about new products and brands" (Cronbach's $\alpha=0.87$ ). Consumer independent judgment making is measured by three items that include "Before I buy a new product or service, I often ask acquaintances about their experiences with that product or service", "Before buying a new brand, I usually ask someone who has experience with the brand for advice", "When considering a new product/service, I usually trust the opinions of friends who have used the product/service" (Cronbach's $\alpha=0.65$ ).

Communication channels include measures of real-world experience with energy sharing, marketing exposure, institutional trust, and trust in social network. Real-world experience with energy sharing is measured via four items, "A friend or neighbor has recently participated in energy sharing", "I know more than one person that participates in energy sharing", "Several people in my neighborhood participate in energy sharing", "I have talked about energy sharing with someone who has already installed the energy-sharing technology in their house" (Cronbach's $\alpha=0.94)$. Exposure to energy-sharing marketing is measured by two items, "In the last six months, I have seen or heard advertisements from companies that facilitate energy sharing" and "My family has recently received advertising or a call from a company that facilitates energy sharing" (Cronbach's $\alpha=0.66$ ). All six of these items are measured as a Yes or No answer. We anticipated that few participants would have real-world experience or exposure to marketing for energy sharing. Institutional trust is measured by three items [58], "I would support having energy sharing in my area regardless of the facilitator", "I would trust any energy-sharing facilitator to make good decisions about energy-sharing technologies", and "I trust any energy-sharing facilitator to keep my best interest in mind" (Cronbach's $\alpha=0.85$ ). Trust in social network is measured by three items, "I trust my friends", "I trust my family", and "I trust my neighbors" (Cronbach's $\alpha=0.60$ ).

The perceived characteristics of the innovation include relative advantage, trialability, riskiness, complexity, and observability. Relative advantage is measured by six items, "Participating in energy sharing would save me money", "Participating in energy sharing provides a great return on a prosumer's investment", "Participating in energy sharing will help protect my family from rising electricity prices in the future", "Participating in 
energy sharing would help meet my family's needs", "Participating in energy sharing could protect my family from electricity blackouts", and "Participating in energy sharing would increase my property value" (Cronbach's $\alpha=0.78$ ). Riskiness is measured by six items [59], "I would worry about participating in energy sharing because it would be an unfamiliar experience", "Participating in energy sharing is a risky thing for a household to do", "Participating in energy sharing could damage my home", "I think energy sharing for residential use is not yet a mature technology", "I don't like the idea of being connected to a server and sharing my energy usage data", "Energy sharing, as described, entails many risks" (Cronbach's $\alpha=0.78$ ). Complexity is measured by three items, "Participating in energy sharing is a hassle", "There is a lot of paperwork involved in participating in energy sharing", "Participating in energy sharing takes a lot of time" (Cronbach's $\alpha=0.73)$. Trialability is measured by five items, "Before contacting an energy-sharing facilitator, I would like to see the participation process up close", "Before considering energy sharing, I would like to talk to someone who uses energy sharing", "If an energy-sharing facilitator tells me how much I would save on my electricity bills by installing solar, I would want a second opinion", and "I would be more interested in energy sharing if there were some way for me to try it out before signing a contract" (Cronbach's $\alpha=0.81$ ). Observability is measured by two items, "I can tell if a community has energy sharing" and "In a community with energy sharing, I can tell who is and is not participating" (Cronbach's $\alpha=0.90$ ).

\subsection{Procedure}

To create a realistic scenario, we described a fictional energy-sharing facilitator, Etopia, to the survey participants. E-topia's mission was to encourage the generation and consumption of solar energy throughout the neighborhood. To participate, participants would use wi-fi enabled smart meters and a mobile app to set a budget or price depending on whether they participated as a prosumer or consumer. Participants were asked to answer the survey questions given this E-topia platform information. We used three multiplechoice questions to measure comprehension of the task based on the information provided in the instructions, including "Which type of participant is able to ONLY buy electricity?" (consumer), "What is energy sharing?" (a marketplace for neighbors to sell excess solar energy to each other), and "What is a prosumer?" (an end-user that has invested in solar installation on their home).

The survey questions were split into three categories, (1) attribute, (2) area, and (3) overall, and question order was randomized within each category. This structure is an approach to minimize order effects suggested by Schreier et al. (2018) [60]. At the end of the survey, participants were asked demographic questions including gender, age, education level, race, employment status, annual income, and electricity supplier.

\subsection{Analysis}

To estimate and evaluate the fit of each behavioral theory, we used structural equation modeling (SEM) via the lavaan package in R [61-63]. This analysis was preregistered on the Open Science Framework before data collection (https:/ /osf.io/s2tgk (accessed on 12 February 2021)). Based on pilot survey results, we modified the wording of the comprehension checks after preregistration. The comprehension checks were modified to include the same terminology to define prosumer and consumer as the E-topia scenario. In this analysis, we do not include evaluation of TPB due to large measurement error in the results. The complete survey, data, and $\mathrm{R}$ code are available on the Open Science Framework (https: / / osf.io/k78vn / (accessed on 8 June 2021)).

In model evaluation, we examine the estimated parameters, variances, and fit indices including the comparative fit index (CFI), Tucker-Lewis index (TLI), Standardized Root Mean Square (SRMR), Cronbach's alpha, standardized factor loadings, and correlation [64,65]. CFI values are always between 0 and 1 and an acceptable model fit is above the threshold of 0.9 [66]. TLI is used to compare the fit of the hypothesized model with the worst-fit model. A recommended TLI value is above 0.9. SRMR measures 
goodness of fit using observed correlation and predicted correlation. A SRMR value is considered good between 0.0 and 0.08 . Cronbach's alpha indicates model consistency and a value greater than 0.7 is considered good. For standardized factor loadings in CFA, a value above 0.7 indicates that sufficient variance is explained [67]. In addition, we compared the findings to a similar model of solar adoption to evaluate robustness for a related technology [22].

\section{Results}

\subsection{Sample}

Of the 200 participants who completed the survey, 5 participants were removed because of data quality issues. They either reported that we should not use their data because they did not take the survey seriously or provided the same response to all of the Likert questions $(\mathrm{N}=195)$. In the sample, 100 participants identified as male $(51 \%), 91$ identified as female (47\%), and 3 chose other options. Most participants were white (132, 68\%), with 19 Black/African American (10\%), 17 Asian (9\%), 10 Hispanic/Latino (5\%), and 1 Native Hawaiian/Pacific Islander participant. Participants ranged from 18 to 78 years old $(M=33, S D=12)$. The majority of the participants were employed full time $(120,62 \%)$ while 26 were employed part time (13\%), 25 were students $(13 \%)$, and 35 chose other options $(18 \%)$. There was a wide range of annual salaries, with most participants earning less than $\$ 60,000 /$ year $(112,57 \%)$ and 79 participants earning more than $\$ 60,000 /$ year $(41 \%)$. As expected, most participants $(131,67 \%)$ had not heard of energy sharing before this study. No participants were removed for failing the comprehension questions and 116 participants (57\%) answered all three comprehension questions correctly. The comprehension questions varied in difficulty, where $94 \%$ correctly recognized the definition of a consumer, $88 \%$ chose the correct definition of energy sharing, and $67 \%$ chose the correct definition of prosumer. There was no correlation between interest in energy sharing and energy sharing knowledge or comprehension of the instructions $(\alpha=0.05)$.

\subsection{Model Specification and Identification}

As reported in the Appendix A, most of the observed variables were reliable (Cronbach's $\alpha>0.70)$. However, for the DOI model, individual judgement, marketing exposure, and social trust had some measurement error (Cronbach's $\alpha>0.60$ ). The Pearson correlations for the variables in each model are summarized in Tables 2 and 3. The numbered columns represent the corresponding numbered row. For example, social curiosity is significantly (low p-value) and strongly (coefficient close to 1) correlated with interest, $r(195)=0.69, p<0.001$. This suggests that participants who expressed higher social curiosity towards energy sharing tended to also indicate higher interest in energy sharing. In general, the VBN model correlations (Table 2) suggest that most of the variables are significant and positively related to interest in energy sharing, except traditional values. Traditional values are more related to duty and do not include environmental aspects. The DOI model correlations (Table 3) suggest that relative advantage, institutional trust, novelty seeking, and consumer independent judgement making are significantly and positively related to interest in energy sharing. This suggests that people are more interested in energy sharing if they perceive it as beneficial, trust-worthy, and new. Riskiness and complexity are significantly and negatively related to interest in energy sharing, suggesting that people are less interested in energy sharing if they perceive it as risky or complex. Trialability, observability, real world experience, marketing exposure, and social trust were not significantly correlated with interest in energy sharing. This is likely because few participants had any real world experience with energy sharing. 
Table 2. Pearson correlation table for VBN. Coefficients that are statistically significantly different from 0 are indicated via $*<<0.05, * * p<0.01, * * *<<0.001$.

\begin{tabular}{|c|c|c|c|c|c|c|c|}
\hline & 1 & 2 & 3 & 4 & 5 & 6 & 7 \\
\hline \multicolumn{8}{|l|}{ 1. Interest } \\
\hline 2. Social Curiosity & $0.69 * * *$ & & & & & & \\
\hline 3. Personal Norm & $0.55 * * *$ & $0.44^{* * *}$ & & & & & \\
\hline 4. Awareness of Consequences & $0.40^{* * *}$ & $0.37^{* * *}$ & $0.69 * * *$ & & & & \\
\hline 5. Altruism & $0.41 * * *$ & $0.36^{* * *}$ & $0.61 * * *$ & $0.36 * * *$ & & & \\
\hline 6. Self-Interest & $0.15^{*}$ & 0.17 * & 0.12 & 0.07 & 0.12 & & \\
\hline 7. Traditional Values & 0.10 & 0.05 & 0.09 & -0.14 & $0.36 * * *$ & $0.35^{* * *}$ & \\
\hline 8. Openness to Change & $0.30^{* * *}$ & $0.44^{* * *}$ & $0.19 * * *$ & 0.05 & $0.28 * * *$ & $0.21^{* *}$ & $0.18^{* *}$ \\
\hline
\end{tabular}

Table 3. Pearson Correlation table for DOI. Coefficients that are statistically significantly different from 0 are indicated via ${ }^{*} p<0.05,{ }^{* *} p<0.01,{ }^{* * *} p<0.001$.

\begin{tabular}{|c|c|c|c|c|c|c|c|c|c|c|c|c|}
\hline & 1 & 2 & 3 & 4 & 5 & 6 & 7 & 8 & 9 & 10 & 11 & 12 \\
\hline 1. Interest & & & & & & & & & & & & \\
\hline 2. Social & $0.69 * * *$ & & & & & & & & & & & \\
\hline $\begin{array}{l}\text { Curiosity } \\
3 \text { Relative }\end{array}$ & & & & & & & & & & & & \\
\hline Advantage & $0.57^{* * *}$ & $0.33^{* * *}$ & & & & & & & & & & \\
\hline 4. Trialability & -0.08 & 0.10 & 0.03 & & & & & & & & & \\
\hline 5. Riskiness & $-0.53^{* * *}$ & $-0.32 * * *$ & $-0.40^{* * *}$ & 0.11 & & & & & & & & \\
\hline $\begin{array}{l}\text { 6. Novelty } \\
\text { Seeking }\end{array}$ & $0.38^{* * *}$ & $0.31^{* * *}$ & $0.38 * * *$ & 0.04 & $-0.28 * * *$ & & & & & & & \\
\hline $\begin{array}{l}\text { 7. Independent } \\
\text { Judgment }\end{array}$ & $0.27^{* * *}$ & $0.36^{* * *}$ & $0.21 * *$ & $0.27^{* * *}$ & -0.11 & $0.34^{* * *}$ & & & & & & \\
\hline 8. Observability & 0.03 & -0.01 & 0.03 & $-0.14^{*}$ & $0.17^{*}$ & $0.16^{*}$ & -0.06 & & & & & \\
\hline $\begin{array}{l}\text { 9. Marketing } \\
\text { Exposure }\end{array}$ & -0.09 & -0.12 & -0.08 & 0.00 & 0.03 & -0.06 & 0.07 & $0.35^{* * *}$ & & & & \\
\hline $\begin{array}{l}\text { 10. Institutional } \\
\text { Trust }\end{array}$ & $0.45^{* * *}$ & $0.27^{* * *}$ & $0.42^{* * *}$ & -0.11 & $-0.35^{* * *}$ & $0.33^{* * *}$ & $0.21 * *$ & $0.29 * * *$ & $-0.18^{*}$ & & & \\
\hline 11. Social Trust & 0.07 & $0.21 * *$ & 0.08 & 0.07 & -0.05 & $0.17^{*}$ & $0.28^{* * *}$ & -0.06 & -0.13 & $0.22 * *$ & & \\
\hline 12. Complexity & $-0.36^{* * *}$ & $-0.24^{* * *}$ & $-0.26^{* * *}$ & 0.11 & $0.71^{* * *}$ & $-0.15^{*}$ & -0.11 & $0.27^{* * *}$ & -0.03 & $-0.24^{* * *}$ & -0.08 & \\
\hline $\begin{array}{l}\text { 13. Real World } \\
\text { Experience }\end{array}$ & 0.10 & 0.03 & 0.08 & $-0.22^{* *}$ & 0.15 * & $0.21 * *$ & -0.02 & $0.91 * * *$ & $-0.34^{* * *}$ & $0.33 * * *$ & -0.03 & $0.24^{* * *}$ \\
\hline
\end{tabular}

\subsection{Model Estimation}

\subsubsection{Value-Belief-Norm (VBN) Model}

The model fit for VBN was approaching acceptable, but did not reach the desired threshold across multiple metrics (CFI $=0.87<0.9, \mathrm{TLI}=0.85<0.9, \mathrm{SRMR}=0.15>0.08$ ). As expected, social curiosity, personal norms, awareness of consequences, altruism, selfinterest, and traditional values were positive predicters in the path model (see Table 4 and Figure 1). Table 4 includes the statistics for each path, or relationship, between two variables in the model. For each path, we report an unstandardized partial coefficient $(\beta)$ to estimate the strength of the relationship, standard error (SE), and p-value for the test of whether the coefficient is statistically significantly different from 0 . Overall, self-interest had the weakest significance and smallest effect, likely due to weak loading of the first question on wealth increasing observed variance (see Table A2). In the CFA, self-interest is largely explained by values related to authority and influence, but not wealth. It is possible that energy sharing aligns with values related to control because the participants are able to set thresholds for how to buy and sell renewable electricity. While altruism and self-interest were positively related to awareness of consequences, traditional values were negatively related. Openness to change was not a significant predictor of awareness of consequences. This is largely consistent with the model of solar adoption measured by Wolske et al. (2017), except we found a relationship between self-interest and awareness of consequences that was not present in the Wolske study [22]. 
Table 4. SEM path coefficients and model fit metrics for Value-Belief-Norm where ${ }^{* *} p<0.01$, $* * * p 0.001$.

\begin{tabular}{cccc}
\hline Path & $\beta$ & SE & $p$-Value \\
\hline Interest $~$ Social Curiosity & 0.78 & 0.11 & $<0.001^{* * *}$ \\
Social Curiosity Personal Norms & 0.49 & 0.06 & $<0.001^{* * *}$ \\
Personal Norms Awareness of Consequences & 0.74 & 0.06 & $<0.001^{* * *}$ \\
Awareness of Consequences $\sim$ Altruism & 0.63 & 0.08 & $<0.001^{* * *}$ \\
Awareness of Consequences Self-Interest & 0.34 & 0.20 & $0.004^{* *}$ \\
Awareness of Consequences $\sim$ Traditional Values & -0.58 & 0.11 & $<0.001^{* * *}$ \\
Awareness of Consequences Openness to Change & -0.15 & 0.10 & 0.05 \\
\hline CFI & 0.87 & & \\
TLI & 0.85 & & \\
AIC & 9702 & & \\
SRMR & 0.15 & &
\end{tabular}

Values

\begin{tabular}{|c|}
\hline $\begin{array}{c}\text { Biospheric/ } \\
\text { Social Altruism }\end{array}$ \\
\hline Self-interest \\
\hline $\begin{array}{c}\text { Traditional } \\
\text { Values }\end{array}$ \\
\hline $\begin{array}{c}\text { Openness to } \\
\text { Change }\end{array}$ \\
\hline
\end{tabular}

Norm

\begin{tabular}{|c|c|c|c|}
\hline Awareness of & al Norm & Social & Interest \\
\hline Consequences & Personal ivorm & Curiosity & \\
\hline
\end{tabular}

Figure 1. Significant SEM pathways for the VBN model. Significant and positive relationships are indicated by a solid line, while negative relationships are indicated with a dashed line.

\subsubsection{Diffusion of Innovation (DOI) Model}

Despite including more variables, the model fit was unacceptable across multiple metrics $(\mathrm{CFI}=0.71<0.9, \mathrm{TLI}=0.67<0.9, \mathrm{SRMR}=0.12>0.08$ ) for the DOI model (See Table 5 and Figure 2). As expected, social curiosity positively predicted interest in participating in energy sharing. Riskiness was a significant negative predictor of social curiosity, suggesting that people are less interested in energy sharing if it is perceived as risky. Observability positively predicts riskiness, suggesting that energy sharing is perceived as riskier if an individual can tell who is and who is not participating. This may be related to concerns about privacy. In addition, novelty seeking and institutional trust negatively predict riskiness, suggesting that energy sharing is perceived as less risky if the institution is trustworthy and the individual enjoys new products.

Trialability and relative advantage did not significantly predict social curiosity about energy sharing. Trialability was positively predicted by consumer independent judgement making and institutional trust, suggesting that energy sharing is perceived as more possible to try out if individuals are able to seek recommendations and the institution is trustworthy. Trialability is negatively predicted by marketing exposure, suggesting that more marketing may not support feelings that an individual can try out the technology. Relative advantage was positively predicted by institutional trust. Overall, this suggests that institutional trust is a key factor that influences multiple aspects of interest in energy sharing. 
Table 5. SEM path coefficients and model fit metrics for Diffusion of Innovation where $p<0.05$, ** $p<0.01,{ }^{* * *} p<0.001$.

\begin{tabular}{|c|c|c|c|}
\hline Path & $\beta$ & SE & $p$-Value \\
\hline Interest $\sim$ Social Curiosity & 0.78 & 0.17 & $<0.01 * * *$ \\
\hline Social Curiosity $\sim$ Relative Advantage & 0.18 & 0.19 & 0.16 \\
\hline Social Curiosity $\sim$ Trialability & 0.14 & 0.10 & 0.25 \\
\hline Social Curiosity $\sim$ Riskiness & -0.27 & 0.11 & $0.04 *$ \\
\hline Riskiness $\sim$ Novelty Seeking & -0.34 & 0.13 & $0.02 *$ \\
\hline Riskiness $\sim$ Independent Judgment & 0.11 & 0.15 & 0.43 \\
\hline Riskiness $\sim$ Observability & 0.57 & 0.11 & $<0.001^{* * *}$ \\
\hline Riskiness $\sim$ Marketing Exposure & 0.00 & 0.45 & 0.99 \\
\hline Riskiness $\sim$ Institutional Trust & -0.45 & 0.13 & $0.003 * *$ \\
\hline Riskiness $\sim$ Social Trust & 0.03 & 0.26 & 0.78 \\
\hline Trialability $\sim$ Novelty Seeking & -0.15 & 0.12 & 0.30 \\
\hline Trialability $\sim$ Independent Judgment & 0.77 & 0.20 & $<0.001^{* * *}$ \\
\hline Trialability $\sim$ Observability & -0.16 & 0.09 & 0.22 \\
\hline Trialability Marketing Exposure & -0.43 & 0.54 & $0.02 *$ \\
\hline Trialability $\sim$ Institutional Trust & 0.51 & 0.12 & $0.001 * *$ \\
\hline Trialability $\sim$ Social Trust & -0.25 & 0.28 & 0.06 \\
\hline Relative Advantage $\sim$ Novelty Seeking & 0.21 & 0.07 & 0.16 \\
\hline Relative Advantage $\sim$ Independent Judgment & 0.10 & 0.09 & 0.96 \\
\hline Relative Advantage $\sim$ Observability & -0.10 & 0.05 & 0.49 \\
\hline Relative Advantage Marketing Exposure & -0.08 & 0.27 & 0.58 \\
\hline Relative Advantage $\sim$ Institutional Trust & 0.34 & 0.07 & 0.03 * \\
\hline \multirow[t]{5}{*}{ Relative Advantage $\sim$ Social Trust } & 0.04 & 0.15 & 0.77 \\
\hline & CFI & 0.71 & \\
\hline & TLI & 0.67 & \\
\hline & AIC & 8,894 & \\
\hline & SRMR & 0.12 & \\
\hline
\end{tabular}

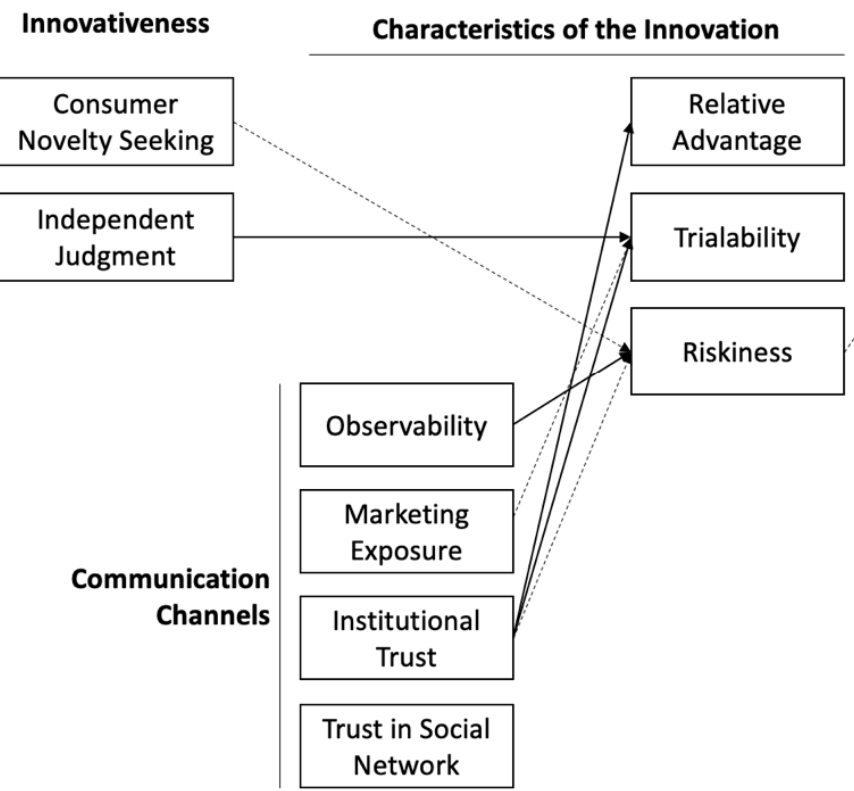

Figure 2. Significant SEM pathways for the DOI model. Significant and positive relationships are indicated by a solid line, while negative relationships are indicated with a dashed line.

Our findings significantly deviated from Wolske et al. (2017) [22]. In Wolske et al. (2017), the predictors of social curiosity were relative advantage and trialability. In contrast, this study did not find those relationships and instead found a negative relationship with 
riskiness. This suggests that, in contrast to solar adoption, more novel technologies like energy sharing may be better predicted by riskiness.

\section{Discussion}

This study estimates and compares the model fit of two behavioral theories, VBN and DOI, to determine which is most appropriate for modeling interest in participating in an energy sharing community. Both theories frame participation in energy sharing in a slightly different way, as a way to achieve internal values or as a novel technology. This study has two primary findings. First, we found that VBN had the better, although still unacceptable, model fit for predicting consumer interest in participating in energy sharing. This suggests that marketing efforts that appeal to consumer values may be most effective. Specifically, participants who were more altruistic, self-interested (in terms of valuing control), and less inclined toward traditional values of duty tended to be more interested in participating in energy sharing. Surprisingly, openness to change was not a significant predictor, despite the fact that energy sharing is a novel technology. From a systems perspective, this suggests that prosumers may be willing to sell electricity for lower prices to align with altruism values and appreciate that they can control the price [16]. Similarly, consumers may be willing to buy electricity via the energy sharing platform even if it is more expensive to align with altruism values and appreciate that they can control price thresholds for when to buy renewable versus grid electricity [16].

Second, the DOI model suggests that riskiness, institutional trust, observability, and novelty seeking may be important factors for driving participation in energy sharing. Riskiness led to reduced interest in energy sharing. Participants tended to perceive energy sharing as riskier if (1) it was observable (i.e., less private), (2) they did not enjoy new products, and (3) if the institution was perceived as less trustworthy. Relative advantage and trialability were not significant predictors, but they were both positively related to institutional trust, suggesting that this is a key factor in determining interest. Overall, the results suggest that VBN may be a more useful model for estimating interest in new energy technologies. However, as the technologies become more well known, other models like DOI may be better. In Wolske et al. (2017), DOI better predicted interest in adopting solar [22].

Most participants had not heard of energy sharing before this study. This posed a measurement as well as an interpretation problem. Due to unfamiliarity with energy sharing, participants may not have had stable perceptions, which increased the variance of some of the observed measures. In addition, there were higher rates of missing data (i.e., responses of "don't know") for constructs in DOI than for constructs in VBN. This suggests personal experience with a technology may directly affect their confidence in responding to survey questions. The DOI model is best suited for early adopters, who were not well represented in this study. These measurement issues likely contributed to the unacceptable model fit. In future work, measurement reliability (as measured by Cronbach's $\alpha$ ) may improve with a larger sample size and more relevant participants. Participants who have already installed clean energy technologies or own their own homes may be more knowledgeable and have more stable preferences related to energy sharing.

In terms of interpretation, there were numerous factors that did not predict interest in energy sharing. For example, openness to change was not a significant factor for VBN but novelty seeking was a significant factor for DOI. In addition, relative advantage was not a significant predictor in DOI, suggesting that individuals did not perceive many benefits of energy sharing. These patterns are likely due to participants' inexperience with energy sharing and first learning about it in this study. Future work may benefit from targeting geographic locations where participants are more likely to have real world familiarity with energy sharing. For example, targeting a study around the Brooklyn Microgrid may find participants who have more stable perceptions about energy sharing. In addition, this study did not distinguish between prosumer and consumer participation, which may influence the motivating factors. For example, DOI is more directly related to 
behavior, while VBN tends to capture more abstract interest. Future work should specify, and potentially experimentally manipulate, this feature to determine the antecedents for different types of participation.

Ultimately, VBN and DOI are unlikely to fully explain consumer behavior, which is not purely rational and highly influenced by social factors. For example, consumers may be sensitive to the institutional context and whether the energy sharing facilitator is a for-profit, non-profit, or co-operative organization. These factors are likely to influence consumer trust and the types of advertising messages employed. In addition, sub-populations (e.g., environmentalists or early adopters) are likely to differ in terms of which models better explain their behavior. Future work should investigate other theoretical approaches from sociology and science and technology studies to explain consumer behavior and motivation within a broader context.

In the context of systems engineering, this study provides insight on how behavioral factors may influence the overall system performance of an energy sharing community. Failing to account for factors such as institutional trust and participant values may lead to the development of business models that struggle with adoption. In addition, optimization for system operation may be improved by using behavioral theories to better account for when and how prosumers and consumers will engage with the system. For example, prosumers who are motivated by altruism may be more willing to decrease prices, or offer electricity for free, in the context of a heat wave, where grid electricity is likely to be the least environmental (due to the use of fossil fuel intensive peaker plants). Rational economic theory would predict prices to increase when there is high demand - but energy sharing communities may find more pro-community results.

Author Contributions: Conceptualization, J.M. and C.C.; methodology, J.M. and C.C.; software, J.M. and C.C.; validation, J.M. and C.C.; formal analysis, J.M. and C.C.; investigation, J.M. and C.C.; resources, J.M.; data curation, J.M.; writing—original draft preparation, J.M.; writing-review and editing, J.M. and C.C.; visualization, J.M. and C.C.; supervision, C.C.; project administration, C.C.; funding acquisition, C.C. Both authors have read and agreed to the published version of the manuscript.

Funding: Julia Morgan is supported by a Graduate Assistance in Areas of National Need (GAANN) fellowship provided by the Department of Education (Project Number P200A180666).

Institutional Review Board Statement: The study was conducted according to the guidelines of the Declaration of Helsinki, and approved by the Institutional Review Board of University of Missouri System (protocol code 2038702 approved on 16 December 2020).

Informed Consent Statement: Informed consent was obtained from all subjects involved in the study.

Data Availability Statement: Data can be found at https:/ / osf.io/k78vn/ (accessed on 8 June 2021).

Acknowledgments: We thank the other students in the Canfield lab group for their insight and support.

Conflicts of Interest: The authors declare no conflict of interest. The funders had no role in the design of the study; in the collection, analyses, or interpretation of data; in the writing of the manuscript, or in the decision to publish the results.

\section{Appendix A}

The standardized factor loadings and confirmatory factor analysis for interest in energy sharing and social curiosity are shown in Table A1. The standardized factor loadings and confirmatory factor analysis for the VBN model are shown in Table A2. The standardized factor loadings and confirmatory factor analysis for the DOI model are shown in Table A3. 
Table A1. Summary of standardized factor loadings in combined confirmatory factor analysis for Interest in Energy Sharing and Social Curiosity.

\begin{tabular}{|c|c|c|}
\hline & $\mathbf{N}$ & $\begin{array}{l}\text { Mean (SD) } \\
\text { Std Ldg }\end{array}$ \\
\hline Interest in Energy Sharing (Cronbach's $\alpha=0.81$ ) & & $3.88(0.83)$ \\
\hline I would be happy to participate in energy sharing even if I have to pay for the total cost & 180 & 0.47 \\
\hline I would switch to energy sharing if I was considering changing my electricity supplier & 183 & 0.75 \\
\hline I would support having energy sharing in my area & 192 & 0.86 \\
\hline I have a positive overall evaluation of energy sharing & 192 & 0.87 \\
\hline Social Curiosity (Cronbach's $\alpha=0.87$ ) & & $4.26(0.81)$ \\
\hline $\begin{array}{c}\text { I would be interested in learning about the cost and benefits of energy sharing if a friend participated in } \\
\text { energy sharing }\end{array}$ & 194 & 0.91 \\
\hline $\begin{array}{l}\text { I would be interested in learning about the cost and benefits of energy sharing if a family member participated } \\
\text { in energy sharing }\end{array}$ & 194 & 0.86 \\
\hline $\begin{array}{c}\text { I would be interested in learning about the cost and benefits of energy sharing if a neighbor participated in } \\
\text { energy sharing }\end{array}$ & 194 & 0.76 \\
\hline
\end{tabular}

Table A2. Summary of standardized factor loadings in combined confirmatory factor analysis for VBN.

\begin{tabular}{|c|c|c|}
\hline Value-Belief-Norm $(\mathrm{CFI}=0.87)$ & $\mathbf{N}$ & $\begin{array}{c}\text { Mean (SD) } \\
\text { Std Ldg }\end{array}$ \\
\hline Altruism (Cronbach's $\alpha=0.90$ ) & & $5.06(0.96)$ \\
\hline Respecting the Earth, harmony with other species & 194 & 0.93 \\
\hline Protecting the environment, preserving nature & 195 & 0.92 \\
\hline A world at peace, free of war and conflict & 193 & 0.64 \\
\hline Unity with nature, fitting into nature & 194 & 0.84 \\
\hline Self-Interest (Cronbach's $\alpha=0.73$ ) & & $3.35(1.14)$ \\
\hline Wealth, material possessions, money & 194 & 0.45 \\
\hline Authority, the right to lead or command & 193 & 0.81 \\
\hline Influential, having an impact on people and events & 193 & 0.83 \\
\hline Traditional Values (Cronbach's $\alpha=0.74$ ) & & $4.75(0.92)$ \\
\hline Honoring parents and elders, showing respect & 195 & 0.85 \\
\hline Family security, safety for loved ones & 194 & 0.58 \\
\hline Self-discipline, self-restraint, resistance to temptation & 194 & 0.66 \\
\hline Openness to Change (Cronbach's $\alpha=0.85$ ) & & $4.68(1.03)$ \\
\hline Curious, interested in everything, exploring & 194 & 0.69 \\
\hline A varied life, filled with challenge, novelty, and change & 195 & 0.83 \\
\hline An exciting life, stimulating experiences & 195 & 0.93 \\
\hline Awareness of Consequences & & $4.51(1.01)$ \\
\hline Climate change is a serious problem for society & 193 & 1.00 \\
\hline Personal Norm (Cronbach's $\alpha=0.90)$ & & $4.02(1.03)$ \\
\hline I feel a personal obligation to do my part to move the country to a renewable energy future & 192 & 0.92 \\
\hline I feel a personal obligation to do my part to prevent climate change & 192 & 0.96 \\
\hline I feel guilty when I waste energy & 193 & 0.73 \\
\hline
\end{tabular}

Table A3. Summary of standardized factor loadings in combined confirmatory factor analysis for DOI.

\begin{tabular}{|c|c|c|}
\hline Diffusion of Innovation $(\mathrm{CFI}=\mathbf{0 . 7 1})$ & $\mathbf{N}$ & $\begin{array}{c}\text { Mean (SD) } \\
\text { Std Ldg }\end{array}$ \\
\hline Novelty Seeking (Cronbach's $\alpha=0.87$ ) & & $3.65(1.02)$ \\
\hline I continuously look for new experiences from new products & 194 & 0.84 \\
\hline I continuously look for new products and brands & 194 & 0.94 \\
\hline I like to visit places where I'm exposed to information and new products and brands & 194 & 0.74 \\
\hline
\end{tabular}


Table A3. Cont.

\begin{tabular}{|c|c|c|}
\hline Diffusion of Innovation (CFI = 0.71) & $\mathbf{N}$ & $\begin{array}{l}\text { Mean (SD) } \\
\text { Std Ldg }\end{array}$ \\
\hline Individual Judgement (Cronbach's $\alpha=0.65)$ & & $4.12(0.71)$ \\
\hline $\begin{array}{c}\text { Before I buy a new product or service, I often ask acquaintances about their experiences with that product } \\
\text { or service }\end{array}$ & 195 & 0.84 \\
\hline Before buying a new brand, I usually ask someone who has experience with the brand for advice & 195 & 0.72 \\
\hline $\begin{array}{c}\text { When considering a new product/service, I usually trust the opinions of friends who have used the } \\
\text { product/service }\end{array}$ & 194 & 0.37 \\
\hline Relative Advantage (Cronbach's $\alpha=0.78$ ) & & $4.20(0.61)$ \\
\hline Participating in energy sharing would save me money & 185 & 0.57 \\
\hline Participating in energy sharing provides a great return on a prosumer's investment & 185 & 0.68 \\
\hline Participating in energy sharing will help protect my family from rising electricity prices in the future & 186 & 0.85 \\
\hline Participating in energy sharing would help meet my family's needs & 190 & 0.77 \\
\hline Participating in energy sharing could protect my family from electricity blackouts & 171 & 0.38 \\
\hline Participating in energy sharing would increase my property value & 172 & 0.53 \\
\hline Riskiness (Cronbach's $\alpha=0.78$ ) & & $2.69(0.89)$ \\
\hline I would worry about participating in energy sharing because it would be an unfamiliar experience & 191 & 0.64 \\
\hline Participating in energy sharing is a risky thing for a household to do & 185 & 0.76 \\
\hline Participating in energy sharing could damage my home & 177 & 0.70 \\
\hline I think energy sharing for residential use is not yet a mature system & 176 & 0.38 \\
\hline I don't like the idea of being connected to a server and sharing my energy usage data & 183 & 0.61 \\
\hline Energy sharing, as described, entails many risks & 193 & 0.68 \\
\hline Complexity (Cronbach's $\alpha=0.73$ ) & & $2.80(0.96)$ \\
\hline Participating in energy sharing is a hassle & 185 & 0.72 \\
\hline There is a lot of paperwork involved in participating in energy sharing & 154 & 0.68 \\
\hline Participating in energy sharing takes a lot of time & 175 & 0.67 \\
\hline Trialability (Cronbach's $\alpha=0.81$ ) & & $4.21(0.69)$ \\
\hline $\begin{array}{c}\text { Before contacting an energy sharing facilitator, I would like to see the technology up close in someone } \\
\text { else's house }\end{array}$ & 195 & 0.76 \\
\hline Before considering energy sharing, I would like to talk to someone who has energy sharing in their home & 195 & 0.88 \\
\hline $\begin{array}{c}\text { If an energy sharing facilitator tells me how much I would save on my electricity bills by installing solar, I } \\
\text { would want a second opinion }\end{array}$ & 193 & 0.42 \\
\hline I would be more interested in energy sharing if there were some way for me to try it out before installing it & 194 & 0.82 \\
\hline Observability (Cronbach's $\alpha=0.90$ ) & & $1.84(0.94)$ \\
\hline I can tell if a community has energy sharing & 178 & 0.96 \\
\hline In a community with energy sharing, I can tell who is participating and who is not & 177 & 0.86 \\
\hline Real World Experience (Cronbach's $\alpha=0.94)$ & & $1.72(1.01)$ \\
\hline A friend or neighbor has recently participated in energy sharing & 150 & 0.91 \\
\hline I know more than one person that participates in energy sharing & 178 & 0.94 \\
\hline Several people in my neighborhood participate in energy sharing & 148 & 0.90 \\
\hline $\begin{array}{l}\text { I have talked about energy sharing with someone who has already installed an energy sharing system in } \\
\text { their home }\end{array}$ & 192 & 0.83 \\
\hline Marketing Exposure (Cronbach's $\alpha=0.66$ ) & & $1.94(0.21)$ \\
\hline In the last six months, I have seen or heard advertisements from companies that facilitate energy sharing & 195 & 0.93 \\
\hline My family has recently received advertising or a call from a company that facilitates energy sharing & 195 & 0.60 \\
\hline Institutional Trust (Cronbach's $\alpha=0.85$ ) & & $3.13(1.18)$ \\
\hline I would trust any energy-sharing facilitator to keep my best interest in mind & 186 & 0.84 \\
\hline I trust any energy-sharing facilitator to keep my best interest in mind & 189 & 0.88 \\
\hline Social Trust (Cronbach's $\alpha=0.60$ ) & & $4.17(0.63)$ \\
\hline I trust my friends & 193 & 0.57 \\
\hline I trust my family & 193 & 0.95 \\
\hline I trust my neighbors & 194 & 0.33 \\
\hline
\end{tabular}




\section{References}

1. Al Shaqsi, A.; Sopian, K.; Al-Hinai, A. Review of Energy Storage Services, Applications, Limitations, and Benefits. Energy Rep. 2020, 6, 288-306. [CrossRef]

2. Pires Klein, L.; Krivoglazova, A.; Matos, L.; Landeck, J.; de Azevedo, M. A Novel Peer-to-Peer Energy Sharing Business Model for the Portuguese Energy Market. Energies 2019, 13, 125. [CrossRef]

3. Mengelkamp, E.; Gärttner, J.; Rock, K.; Kessler, S.; Orsini, L.; Weinhardt, C. Designing microgrid energy markets: A case study: The Brooklyn Microgrid. Appl. Energy 2018, 210, 870-880. [CrossRef]

4. Monsberger, C.; Fina, B.; Auer, H. Profitability of Energy Supply Contracting and Energy Sharing Concepts in a Neighborhood Energy Community: Business Cases for Austria. Energies 2021, 14, 921. [CrossRef]

5. Mucha-Kus, K.; Soltysik, M.; Zamasz, K.; Szczepanska-Woszczyna, K. Coopetitive Nature of Energy Communities-The Energy Transition Context. Energies 2021, 14, 931. [CrossRef]

6. Smale, R.; Kloppenburg, S. Platforms in Power: Householder Perspectives on the Social, Environmental and Economic Challenges of Energy Platforms. Sustainability 2020, 12, 692. [CrossRef]

7. Celik, B.; Roche, R.; Bouquain, D.; Miraoui, A. Decentralized Neighborhood Energy Management with Coordinated Smart Home Energy Sharing. IEEE Trans. Smart Grid. 2018, 9, 6387-6397. [CrossRef]

8. Jacobs, S. The Energy Prosumer. Ecol. Law Q. 2016, 43, 519-579.

9. Cui, S.; Wang, Y.; Li, C.; Xiao, J. Prosumer Community: A Risk Aversion Energy Sharing Model. IEEE Trans. Sustain. Energy. 2020, 11, 828-838. [CrossRef]

10. Fleischhacker, A.; Auer, H.; Lettner, G.; Botterud, A. Sharing Solar PV and Energy Storage in Apartment Buildings: Resource Allocation and Pricing. IEEE Trans. Smart Grid. 2019, 10, 3963-3973. [CrossRef]

11. Wiser, R.; Olson, S.; Bird, L.; Swezey, B. Utility Green Pricing Programs: A Statistical Analysis of Program Effectiveness. Energy Environ. 2005, 16, 47-68. [CrossRef]

12. Bird, L.; Cochran, J.; Wang, X. Wind and Solar Energy Curtailment: Experience and Practices in the United States; National Renewable Energy Laboratory (NREL): Golden, CO, USA, 2014.

13. Bunodiere, A.; Lee, H. Renewable Energy Curtailment: Prediction Using a Logic-Based Forecasting Method and Mitigation Measures in Kyushu, Japan. Energies 2020, 13, 4703. [CrossRef]

14. Sanguinetti, A.; McIlvennie, C.; Pritoni, M.; Schneider, S. Beyond Curtailment and Efficiency: Identifying Household Energy and Water Saving Measure Classes; Lawrence Berkeley National Laboratory: Berkeley, CA, USA, 2020.

15. Tarka, P. An Overview of Structural Equation Modeling: Its Beginnings, Historical Development, Usefulness and Controversies in the Social Sciences. Qual. Quant. 2017, 52, 313-354. [CrossRef]

16. Morgan, J.; Qin, R. Modeling and Understanding Energy Sharing Communities: A System of Systems Approach. In Proceedings of the International Annual Conference of the American Society for Engineering Management, Coeur d'Alene, ID, USA, 17-20 October 2018.

17. Belk, R. You Are What You Can Access: Sharing and Collaborative Consumption Online. J. Bus. Res. 2014, 67, 1595-1600. [CrossRef]

18. Islam, S.; Rathnam, E.; Chau, S.; Ward, J. Optimization-Based Energy Sharing Among Customers for Enhanced Resilience in a Community Microgrid. In Proceedings of the Eleventh ACM International Conference on Future Energy Systems, Melbourne, Australia, 22-26 June 2020; pp. 413-414.

19. Sun, Y.; Cai, Z.; Zhang, Z.; Guo, C.; Ma, G. Coordinated Energy Scheduling of a Distributed Multi-Microgrid System Based on Multi-Agent Decisions. Energies 2020, 13, 4077. [CrossRef]

20. Tsou, H.; Chen, J.; Chou, C.; Chen, T. Sharing Economy Service Experience and Its Effects on Behavioral Intention. Sustainability 2019, 11, 5050. [CrossRef]

21. Conradie, P.; Ruyck, O.; Saldien, J.; Ponnet, K. Who Wants to Join a Renewable Energy Community in Flanders? Applying an Extended Model of Theory of Planned Behaviour to Understand Intent to Participate. Energy Policy 2021, 161, 112121. [CrossRef]

22. Wolske, K.; Stern, P.; Dietz, T. Explaining Interest in Adopting Residential Solar Photovoltaic Systems in the United States: Toward an Integration of Behavioral Theories. Energy Res. Soc. Sci. 2017, 25, 134-151. [CrossRef]

23. Liu, N.; Guo, B. Multi-Party Optimal Operation for Distribution Networks Containing DC-Linked Microgrids: Integrated Network Reconfigurations and Energy Sharing. Appl. Sci. 2017, 7, 1194. [CrossRef]

24. Giordano, A.; Mastroianni, C.; Scarcello, L. Optimization Model for IoT-Aware Energy Exchange in Energy Communities for Residential Users. Electronics 2020, 9, 1003. [CrossRef]

25. Zhang, K.; Guo, H.; Yao, G.; Li, C.; Zheng, Y.; Wang, W. Modeling Acceptance of Electric Vehicle Sharing Based on Theory of Planned Behavior. Sustainability 2018, 10, 4686. [CrossRef]

26. Macovei, O. Applying the Theory of Planned Behavior in Predicting Proenvironmental Behaviour: The Case of Energy Conservation. Acta Universitatis Danubius. CEconomica 2015, 11, 15-32.

27. Clement, C. Integrating Factors that Predict Energy Conservation: The Theory of Planned Behavior and Beliefs about Climate Change. JSD J. Sustain. Dev. 2014, 7. [CrossRef]

28. Stern, P. New Environmental Theories: Toward a Coherent Theory of Environmentally Significant Behavior. J. Soc. Issues 2002, 56, 407-424. [CrossRef] 
29. Schwartz, S. Universals in the Content and Structure of Values: Theoretical Advances and Empirical Tests in 20 Countries. Adv. Exp. Soc. Psychol. 1990, 25, 1-65.

30. Schwartz, S.H. Normative influences on altruism. Adv. Exp. Soc. Psychol. 1977, 10, 221-279.

31. Stern, P.; Dietz, T.; Abel, T.; Guagnano, G.; Kalof, L. A Value-Belief-Norm Theory of Support for Social Movements: The Case of Environmentalism. Res. Hum. Ecol. 1999, 6, 81-97.

32. Ghazali, E.; Nguyen, B.; Mutum, D.; Yap, S. Pro-Environmental Behaviours and Value-Belief-Norm Theory: Assessing Unobserved Heterogeneity of Two Ethnic Groups. Sustainability 2019, 11, 3237. [CrossRef]

33. Sánchez, M.; López-Mosquera, N.; Lera-López, F.; Faulin, J. An Extended Planned Behavior Model to Explain the Willingness to Pay to Reduce Noise Pollution in Road Transportation. J. Clean. Prod. 2018, 177, 144-154. [CrossRef]

34. Dono, J.; Webb, J.; Richardson, B. The Relationship Between Environmental Activism, Pro-Environmental Behaviour and Social Identity. J. Environ. Psychol. 2010, 30, 178-186. [CrossRef]

35. Andersson, K.; Jagers, S.; Lindskog, A.; Martinsson, J. Learning for the Future? Effects for Education for Sustainable Development (ESD) on Teacher Education Students. Sustainability 2013, 5, 5135-5152. [CrossRef]

36. Claudy, M.C.; Peterson, M.; O'driscoll, A. Understanding the attitude-behavior gap for renewable energy systems using behavioral reasoning theory. J. Macromarketing 2013, 33, 273-287. [CrossRef]

37. Kiatkawsin, K.; Han, H. Young travelers' intention to behave pro-environmentally: Merging the value-belief-norm theory and the expectancy theory. Tour. Manag. 2017, 59, 76-88. [CrossRef]

38. Rogers, E. Diffusion of Innovations; The Free Press of Glencoe: New York, NY, USA, 1962.

39. Dearing, J.; Cox, G. Diffusion of Innovations Theory, Principles, and Practice. Health Aff. 2018, 37, 183-190. [CrossRef] [PubMed]

40. Bick, M. Reviewed Work: Diffusion of Innovations by Everett M. Rogers. Am. Anthropol. New Ser. 1963, 65, 1146-1147. [CrossRef]

41. Beets, M.; Flay, B.; Vuchinich, S.; Acock, A.; Li, K.; Allred, C. School Climate and Teachers' Beliefs and Attitudes Associated with Implementation of the Positive Action Program: A Diffusion of Innovations Model. Prev. Sci. 2008, 9, 265-275. [CrossRef]

42. Atun, R.; Kyratsis, I.; Jelic, G.; Rados-Malicbegovic, D.; Gurol-Urganci, I. Diffusion of Complex Health InnovationsImplementation of Primary Health Care Reforms in Bosnia and Herzegovina. Health Policy Plan. 2007, 22, 28-39. [CrossRef]

43. Geola, G. The Diffusion of Grassroots Innovations for Sustainability in Italy and Great Britain: An Exploratory Spatial Data Analysis. Geogr. J. 2017, 183, 16-33.

44. Al Othman, F.; Sohaib, O. Enhancing Innovative Capability and Sustainability of Saudi Firms. Sustainability 2016, 8, 1229. [CrossRef]

45. Abell, P.; Wynn, H. Smart Democracy: Facilitating Technological Change; London School of Economics: London, UK, 2013.

46. MacVaugh, J.; Schiavone, F. Limits to the diffusion of innovation: A literature review and integrative model. Eur. J. Innov. Manag. 2010, 13, 197-221. [CrossRef]

47. Taylor, S. Decomposition and Crossover Effects in the Theory of Planned Behavior: A Study of Consumer Adoption Intentions. Int. J. Res. Mark. 1995, 12, 137-155. [CrossRef]

48. Palan, S.; Schitter, C. Prolific. ac-A subject pool for online experiments. J. Behav. Exp. Financ. 2018, 17, 22-27. [CrossRef]

49. Peer, E.; Brandimarte, L.; Samat, S.; Acquisti, A. Beyond the Turk: Alternative platforms for crowdsourcing behavioral research. J. Exp. Soc. Psychol. 2017, 70, 153-163. [CrossRef]

50. Newman, A.; Bavik, Y.L.; Mount, M.; Shao, B. Data Collection Via Online Platforms: Challenges and Recommendations for Future Research. Appl. Psychol. 2021, 70, 1380-1402. [CrossRef]

51. Wolf, E.; Harrington, K.; Clark, S.; Miller, M. Sample Size Requirements for Structural Equation Models: An Evaluation of Power, Bias, and Solution Propriety. Educ. Psychol. Meas. 2013, 73, 913-934. [CrossRef] [PubMed]

52. Boomsma, A. Nonconvergence, Improper Solutions, and Starting Values in LISREL Maximum Likelihood Estimation. Psychometrika 1985, 50, 229-242. [CrossRef]

53. Taber, J.; Ellis, E.; Reblin, M.; Ellington, L.; Ferrer, R. Knowledge of and Beliefs about Palliative-Care in a Nationally Representative U.S. Sample. PLoS ONE 2019, 14, e0219074. [CrossRef]

54. Hartung, F.; Renner, B. Social Curiosity and Interpersonal Perception: A Judge x Trait Interaction. Personal. Soc. Psychol. Bull. 2011, 37, 796-814. [CrossRef]

55. Dietz, T. Environmental values. In Oxford Handbook of Values; Bosch, T., Sander, D., Eds.; Oxford University Press: Oxford, UK, 2015; pp. 329-349.

56. Jansson, J. Consumer Eco-innovation Adoption: Assessing Attitudinal Factors and Perceived Product Characteristics. Bus. Strategy Environ. 2011, 20, 192-210. [CrossRef]

57. Manning, K.; Bearden, W.; Madden, T. Consumer Innovativeness and the Adoption Process. J. Consum. Psychol. 1995, 4, 329-345. [CrossRef]

58. Queiroz, M.; Wamba, S. Blockchain Adoption Challenges in Supply Chain: An Empirical Investigation of the Main Drivers in India and the USA. Int. J. Inf. Manag. 2018, 46, 70-82. [CrossRef]

59. Ambrosio-Albala, P.; Upham, P.; Bale, C.S.E.; Taylor, P.G. Exploring Acceptance of Decentralised Eneryg Storage at Household and Neighbourhood Scales: A UK Survey. Energy Policy 2019, 123, 111-194.

60. Schreier, J.; Biethahn, N.; Drewes, F. Question Order Effects in Partial Least Squares Path Modelling: An Empirical Investigation. Qual. Quant. 2017, 52, 71-84. [CrossRef] 
61. Rosseel, Y. Lavaan: An R package for structural equation modeling and more. Version 0.5-12 (BETA). J. Stat. Softw. 2012, 48, 1-36. [CrossRef]

62. Oberski, D. Lavaan. survey: An R package for complex survey analysis of structural equation models. J. Stat. Softw. 2014, 57, 1-27. [CrossRef]

63. Fox, J. Teacher's corner: Structural equation modeling with the sem package in R. Struct. Equ. Modeling 2006, 13, 465-486. [CrossRef]

64. Hox, J.J.; Bechger, T.M. An introduction to structural equation modeling. Fam. Sci. Rev. 1998, 11, 354-373.

65. Weston, R.; Gore, P. A Brief Guide to Structural Equation Modeling. Couns. Psychol. 2006, 34, 719-751. [CrossRef]

66. Hu, L.T.; Bentler, P.M. Cutoff criteria for fit indexes in covariance structure analysis: Conventional criteria versus new alternatives. Struct. Equ. Modeling Multidiscip. J. 1999, 6, 1-55. [CrossRef]

67. Anderson, J.; Gerbing, D. The Effect of Sampling Error on Convergence, Improper Solutions, and Goodness-of-fit Indices for Maximum Likelihood Confirmatory Factor Analysis. Psychometrika 1984, 49, 155-173. [CrossRef] 